\title{
Editorial: Probing the Cardiac Arm of the Baroreflex and Complementary Branches
}

\author{
Alberto Porta ${ }^{1,2 *}$ and Maja Elstad ${ }^{3}$ \\ ${ }^{1}$ Department of Biomedical Sciences for Health, University of Milan, Milan, Italy, ${ }^{2}$ Department of Cardiothoracic, Vascular \\ Anesthesia and Intensive Care, IRCCS Policlinico San Donato, Milan, Italy, ${ }^{3}$ Division of Physiology, Institute of Basic Medical \\ Sciences, University of Oslo, Oslo, Norway
}

Keywords: heart rate variability, arterial blood pressure, sympathetic neural activity, cardiovascular control, peripheral resistances, autonomic nervous system, baroreflex sensitivity

\section{Editorial on the Research Topic}

\section{Probing the Cardiac Arm of the Baroreflex and Complementary Branches}

Baroreflex (BR) is one of the most important mechanisms in short-term regulation of arterial pressure (AP) (Robertson et al., 2012). The BR has a key role in limiting excessive AP rises via the activation of a vagal reflex (Robertson et al., 2012) producing several consequences on physiological variables. The most frequently evaluated consequence is the lengthening of heart period (HP) (Pickering et al., 1972). Baroreflex is crucial in bipedal animals like humans to prevent AP drops while standing via a sympathetic activation eliciting the HP shortening (Montano et al., 1994; Cooke et al., 1999; Marchi et al., 2016; De Maria et al., 2018) and the increase of burst rate of integrated postganglionic efferent sympathetic nerve activity directed to muscles (Sundlof and Wallin, 1978; Cooke et al., 1999; Furlan et al., 2000; Marchi et al., 2016). The BR engagement limits

\section{OPEN ACCESS}

Edited and reviewed by:

Vaughan G. Macefield,

Baker Heart and Diabetes Institute, Australia

*Correspondence:

Alberto Porta

alberto.porta@unimi.it

Specialty section: This article was submitted to Autonomic Neuroscience, a section of the journal

Frontiers in Neuroscience

Received: 05 December 2019 Accepted: 16 December 2019 Published: 10 January 2020

Citation:

Porta A and Elstad M (2020) Editorial: Probing the Cardiac Arm of the Baroreflex and Complementary Branches. Front. Neurosci. 13:1422. doi: 10.3389/fnins.2019.01422 excessive AP variability in both humans and animals (Bertinieri et al., 1988; Parati et al., 1988; Frankel et al., 1993; Porta et al., 2000; Fazan et al., 2005).

The clinical evaluation of the BR control started with Smyth et al. (1969) who provided a practical, even though invasive, way to characterize $\mathrm{BR}$ via the estimate of the baroreflex sensitivity (BRS), namely the magnitude of HP changes observed in response to a pharmacologically induced unit variation of systolic AP (SAP). This interventional method is predictive for clinical outcomes (La Rovere et al., 1998) but, as it is inherently both non-physiological and invasive, researchers proposed noninvasive, non-interventional, and non-pharmacological surrogate techniques based on spontaneous fluctuations of HP and SAP with the aim at enlarging and favoring clinical applications (Laude et al., 2004). Both interventional and noninterventional techniques made the $\mathrm{BR}$ assessment popular but they contributed to form the common belief that $\mathrm{BR}$ is coincident with its cardiac arm operating to keep AP constant via $\mathrm{HP}$ adjustments. However, cardiac BR ( $\mathrm{CBR})$ is neither the unique arm of the $\mathrm{BR}$ nor the most important one, given that recent heart transplanted patients can stand up (Smith et al., 1989; Karemaker and Wesseling, 2008) and technologies for baroreflex failure target directly vasomotor sympathetic nerves (Hosokawa and Sunagawa, 2016). One of the consequences of the view identifying the $\mathrm{BR}$ with $\mathrm{cBR}$ is the tendency of interpreting modifications of the mean AP experienced during everyday life in spite of homeostatic characteristic of the BR as a result of its noisy nature (Karemaker and Wesseling, 2008). Conversely, the stochastic nature of the $\mathrm{BR}$ might be the simple consequence of its complex and composite nature: indeed, since the BR can target several physiological variables including heart rate, sympathetic activity, peripheral resistances, cardiac contractility, and stroke volume just to mention a few 
(Smyth et al., 1969; Sundlof and Wallin, 1978; Casadei et al., 1992; Kienbaum et al., 2001; Yasumasu et al., 2005; Vaschillo et al., 2012; Borgers et al., 2014; Barbic et al., 2015; Elstad et al., 2015; Hosokawa and Sunagawa, 2016; Reyes del Paso et al., 2017; Porta et al., 2018) and since the functioning of all these branches is weakly correlated as it appears from the weak correlation among BRSs (Rudas et al., 1999; O'Leary et al., 2003; Dutoit et al., 2010; Taylor et al., 2015; Marchi et al., 2016), it is not surprising to observe that mean AP does not always obey to the homeostatic principle. The composite nature of the $\mathrm{BR}$ is compatible with the observation that short-term fluctuations of HP are not intimately and always linked to those of SAP (Diaz and Taylor, 2006).

The aim of this Research Topic is, on the one hand, to stress the composite nature of the BR and the need of overcome a description solely based on the assessment of the $\mathrm{CBR}$ and, on the other hand, the possibility to provide a more complete, and faithful, description of the $\mathrm{BR}$ based on the use of a multivariate integrated approach exploiting simultaneous recordings of several physiological variables and state-of-the-art signal processing techniques applied to their spontaneous fluctuations. Among the most relevant challenges that need to be faced to make this approach successful we recall the inherent difficulty posed by the small amplitude of the spontaneous SAP fluctuations in assuring a BR description uncorrupted by confounding mechanisms operating in causal directions incompatible with a BR engagement (Porta et al., 2000, 2013; Diaz and Taylor, 2006).

\section{REFERENCES}

Barbic, F., Heusser, K., Marchi, A., Zamunér, A. R., Gauger, P., Tank, J., et al. (2015). Cardiovascular parameters and neural sympathetic discharge variability before orthostatic syncope: role of sympathetic baroreflex control to the vessels. Physiol. Meas. 36, 633-641. doi: 10.1088/0967-3334/36/4/633

Bertinieri, G., Di Rienzo, M., Cavallazzi, A., Ferrari, A. U., Pedotti, A., and Mancia, G. (1988). Evaluation of baroreceptor reflex by blood pressure monitoring in unanesthetized cats. Am. J. Physiol. 254, H377-H383. doi: 10.1152/ajpheart.1988.254.2.H377

Borgers, A. J., van den Born, B.-J., Alkemade, A., Eeftinck Schattenkerk, D. W., van Lieshout, J. J., Wesseling, K. H., et al. (2014). Determinants of vascular and cardiac baroreflex sensitivity values in a random population sample. Med. Biol. Eng. Comput. 52, 65-73. doi: 10.1007/s11517-013-1111-0

Casadei, B., Meyer, T. E., Coats, A. J., Conway, J., and Sleight, P. (1992). Baroreflex control of stroke volume in man: an effect mediated by the vagus. J. Physiol. 448, 539-550. doi: 10.1113/jphysiol.1992.sp019056

Cooke, W. H., Hoag, J. B., Crossman, A. A., Kuusela, T. A., Tahvanainen, K. U. O., and Eckberg, D. L. (1999). Human responses to upright tilt: a window on central autonomic integration. J. Physiol. 517, 617-628. doi: 10.1111/j.1469-7793.1999.0617t.x

De Maria, B., Bari, V., Ranucci, M., Pistuddi, V., Ranuzzi, G., Takahashi, A. C. M., et al. (2018). Separating arterial pressure increases and decreases in assessing cardiac baroreflex sensitivity via sequence and bivariate phaserectified signal averaging techniques. Med. Biol. Eng. Comput. 56, 1241-1252. doi: $10.1007 /$ s11517-017-1765-0

Diaz, T., and Taylor, J. A. (2006). Probing the arterial baroreflex: is there a 'spontaneous' baroreflex? Clin. Auton. Res. 16, 256-261. doi: 10.1007/s10286-006-0352-5

Dutoit, A. P., Hart, E. C., Charkoudian, N., Wallin, B. G., Curry, T. B., and Joyner, M. J. (2010). Cardiac baroreflex sensitivity is not correlated to
In this Research Topic the complexity and composite nature of the BR and its assessment is illustrated by the diversity in the contributions. They stress the relevance of the simultaneous assessment of cardiac and sympathetic arms of the BR in healthy subjects (Barbic et al.) and patients (Brunetta et al.), the different characteristics of the BR arms likely to contribute to their weakly correlated behaviors (De Maria et al.), the importance of the clinical information that can be derived from BR markers estimated from spontaneous variability (Bari et al. and Solaro et al.), the chance of elucidating the brainstem nuclei functioning involved in the modulation of the activity of all BR branches (Gerlach et al.), the importance of modeling the dynamical interactions among variables via modeling approaches accounting for directionality (Chalacheva et al.) and feedforward influences (Parati et al.), the possibility given by advanced signal processing tools to provide a more insightful description of the complex behavior of the cBR arm (de Boer and Karemaker) and to limit the effects of confounding factors (Silva et al.), and the opportunity of exploiting smart technologies to broaden the range of applications of $\mathrm{BR}$ monitoring (Lázaro et al.). We hope this Research Topic contributes to understanding the complex nature of the BR and its assessment.

\section{AUTHOR CONTRIBUTIONS}

AP and ME conceived the contribution, drafted the manuscript, edited and revised the manuscript, and approved the final version of the manuscript.

sympathetic baroreflex sensitivity within healthy young humans. Hypertension 56, 1118-1123. doi: 10.1161/HYPERTENSIONAHA.110.158329

Elstad, M., Walløe, L., Holme, N. L., Maes, E., and Thoresen, M. (2015). Respiratory sinus arrhythmia stabilizes mean arterial blood pressure at highfrequency interval in healthy humans. Eur. J. Appl. Physiol. 115, 521-530. doi: 10.1007/s00421-014-3042-3

Fazan, R. Jr., de Oliveira, M., da Silva, V. J., Joaquim, L. F., Montano, N., Porta, A., et al. (2005). Frequency-dependent baroreflex modulation of blood pressure and heart rate variability in conscious mice. Am. J. Physiol. 289, H1968-H1975. doi: 10.1152/ajpheart.01224.2004

Frankel, R. A., Metting, P. J., and Britton, S. L. (1993). Evaluation of spontaneous baroreflex sensitivity in conscious dogs. J. Physiol. 462, 31-45. doi: 10.1113/jphysiol.1993.sp019541

Furlan, R., Porta, A., Costa, F., Tank, J., Baker, L., Schiavi, R., et al. (2000). Oscillatory patterns in sympathetic neural discharge and cardiovascular variables during orthostatic stimulus. Circulation 101, 886-892. doi: 10.1161/01.CIR.101.8.886

Hosokawa, K., and Sunagawa, K. (2016). Closed-Loop neuromodulation technology for baroreflex blood pressure control. Proc. IEEE 104, 432-443. doi: 10.1109/JPROC.2015.2496290

Karemaker, J. M., and Wesseling, K. H. (2008). Variability in cardiovascular control: the baroreflex reconsidered. Cardiovasc. Eng. 8, 23-29. doi: 10.1007/s10558-007-9046-4

Kienbaum, P., Karlsson, T., Sverrisdottir, Y. B., Elam, M., and Wallin, B. G. (2001). Two sites for modulation of human sympathetic activity by arterial baroreceptors. J. Physiol. 531, 861-869. doi: 10.1111/j.1469-7793.2001.0861h.x

La Rovere, M. T., Bigger, J. T. Jr., Marcus, F. I., Mortara, A., and Schwartz, P. J. (1998). Baroreflex sensitivity and heart-rate variability in prediction of total cardiac mortality after myocardial infarction. ATRAMI (Autonomic Tone and Reflexes After Myocardial Infarction) Investigators. Lancet 351, 478-484. doi: 10.1016/S0140-6736(97)11144-8 
Laude, D., Elghozi, J. L., Girard, A., Bellard, F., Bouhaddi, M., Castiglioni, P., et al. (2004). Comparison of various techniques used to estimate spontaneous baroreflex sensitivity (the EuroBaVar study). Am. J. Physiol. 286, R226-R231. doi: 10.1152/ajpregu.00709.2002

Marchi, A., Bari, V., De Maria, B., Esler, M., Lambert, E., Baumert, M., et al. (2016). Simultaneous characterization of sympathetic and cardiac arms of the baroreflex through sequence techniques during incremental head-up tilt. Front. Physiol. 7:438. doi: 10.3389/fphys.2016. 00438

Montano, N., Gnecchi-Ruscone, T., Porta, A., Lombardi, F., Pagani, M., and Malliani, A. (1994). Power spectrum analysis of heart rate variability to assess changes in sympatho-vagal balance during graded orthostatic tilt. Circulation 90, 1826-1831. doi: 10.1161/01.CIR.90.4.1826

O'Leary, D. D., Kimmerly, D. S., Cechetto, A. D., and Shoemaker, J. K. (2003). Differential effect of head-up tilt on cardiovagal and sympathetic baroreflex sensitivity in humans. Exp. Physiol. 88, 769-774. doi: 10.1113/eph8802632

Parati, G., di Rienzo, M., Bertinieri, G., Pomidossi, G., Casadei, R., Groppelli, A., et al. (1988). Evaluation of the baroreceptor-heart rate reflex by 24-hour intra-arterial blood pressure monitoring in humans. Hypertension 12, 214-222. doi: 10.1161/01.HYP.12.2.214

Pickering, T. G., Gribbin, B., and Sleight, P. (1972). Comparison of the reflex heart rate response to rising and falling arterial pressure in man. Cardiovasc. Res. 6, 277-283. doi: 10.1093/cvr/6.3.277

Porta, A., Bari, V., De Maria, B., Cairo, B., Vaini, E., Malacarne, M., et al. (2018). Peripheral resistance baroreflex during incremental bicycle ergometer exercise: characterization and correlation with cardiac baroreflex. Front. Physiol. 9:688. doi: $10.3389 /$ fphys.2018.00688

Porta, A., Baselli, G., Rimoldi, O., Malliani, A., and Pagani, M. (2000). Assessing baroreflex gain from spontaneous variability in conscious dogs: role of causality and respiration. Am. J. Physiol. 279, H2558-H2567. doi: 10.1152/ajpheart.2000.279.5.H2558

Porta, A., Castiglioni, P., Di Rienzo, M., Bassani, T., Bari, V., Faes, L., et al. (2013). Cardiovascular control and time domain Granger causality: insights from selective autonomic blockade. Phil. Trans. R Soc. A 371:20120161. doi: 10.1098/rsta.2012.0161

Reyes del Paso, G. A., de la Coba, P., Martín-Vazquez, M., and Thayer, J. F. (2017). Time domain measurement of the vascular and myocardial branches of the baroreflex: a study in physically active versus sedentary individuals. Psychophysiology 54, 1528-1540. doi: 10.1111/psyp.12898
Robertson, D., Diedrich, A., and Chapleau, M. W. (2012). Editorial on arterial baroreflex issue. Auton. Neurosci. -Basic Clin. 172, 1-3. doi: 10.1016/j.autneu.2012.10.010

Rudas, L., Crossman, A. A., Morillo, C. A., Halliwill, J. R., Tahvanainen, K. U. O., Kuusela, T. A., et al. (1999). Human sympathetic and vagal baroreflex responses to sequential nitroprusside and phenylephrine. Am. J. Physiol. 276, H1691-H1698. doi: 10.1152/ajpheart.1999.276.5.H1691

Smith, M. L., Ellenbogen, K. A., Eckberg, D. L., Szentpetery, S., and Thames, M. D. (1989). Subnormal heart period variability in heart failure: effect of cardiac transplantation. J. Am. Coll. Cardiol. 14, 106-111. doi: 10.1016/0735-1097(89)90059-4

Smyth, H. S., Sleight, P., and Pickering, G. W. (1969). Reflex regulation of arterial pressure during sleep in man. A quantitative method of assessing baroreflex sensitivity. Circ. Res. 24,109-121. doi: 10.1161/01.RES.24.1.109

Sundlof, G., and Wallin, B. G. (1978). Human muscle nerve sympathetic activity at rest. Relationship to blood pressure and age. J. Physiol. 274, 621-637. doi: 10.1113/jphysiol.1978.sp012170

Taylor, C. E., Witter, T., El Sayed, K., Hissen, S. L., Johnson, A. W., and Macefield, V. G. (2015). Relationship between spontaneous sympathetic baroreflex sensitivity and cardiac baroreflex sensitivity in healthy young individuals. Physiol. Rep. 3:e12536. doi: 10.14814/phy2.12536

Vaschillo, E. G., Vaschillo, B., Buckman, J. F., Pandina, R. J., and Bates, M. E. (2012). Measurement of vascular tone and stroke volume baroreflex gain. Psychophysiology 49, 193-197. doi: 10.1111/j.1469-8986.2011.01305.x

Yasumasu, T., Abe, H., Oginosawa, Y., Takahara, K., and Nakashima, Y. (2005). Assessment of cardiac baroreflex function during fixed atrioventricular pacing using baroreceptor-stroke volume reflex sensitivity. J. Cardiovasc. Electrophysiol. 16, 727-731. doi: 10.1111/j.1540-8167.2005.40767.x

Conflict of Interest: The authors declare that the research was conducted in the absence of any commercial or financial relationships that could be construed as a potential conflict of interest.

Copyright (c) 2020 Porta and Elstad. This is an open-access article distributed under the terms of the Creative Commons Attribution License (CC BY). The use, distribution or reproduction in other forums is permitted, provided the original author(s) and the copyright owner(s) are credited and that the original publication in this journal is cited, in accordance with accepted academic practice. No use, distribution or reproduction is permitted which does not comply with these terms. 